\title{
Active Internationalization of Software Enterprises: Scale Development and Validation
}

\author{
Maurício Floriano Galimberti ${ }^{*}$, Andreia Zanella ${ }^{1}$
}

\begin{abstract}
A 34-item scale was developed to measure the attributes that contribute to success in the active internationalization processes of small and medium enterprises of software. Data from 103 companies was analysed. The scale was developed and available online in 4 languages. Based on established scale development procedures, such as exploratory and confirmatory factorial analysis, a final version of the research scale was proposed, composed by 15 items grouped in 4 dimensions. Innovation, entrepreneurship, network, and foreign market knowledge appear to be important factors for the success in the active internationalization processes of small and medium enterprise of software. Reliability and validity measures were calculated in order to check the adequacy of the proposed model. Concluding remarks discuss theoretical and managerial implications with limitations and directions for future research.
\end{abstract}

Keywords: active internationalization; small and medium-sized software enterprises; scale development; software SMEs; internationalization of software enterprises.

Submitted: May 2 $2^{\text {nd }}, 2018$ / Approved: June $12^{\text {th }}, 2019$

\section{Introduction}

Even with large domestic markets, internationalization can be characterized as an efficient strategy, especially in the case of small and medium-sized software enterprises (SMEs). internationalization can be a key instrument for strengthening companies and increasing the competitiveness of countries in an environment of fierce international competition. Factors such as increased access to technology, dilution of $\mathrm{R} \& \mathrm{D}$ costs when there is an increase in the scale of production, incoming of profits and dividends by affiliates, and increased brand visibility in foreign markets may result in increased credibility, both external and internal, which would also be a factor of protection and expansion in the domestic market.

Although internationalization of software SMEs is increasing in several regions of the world, the theories and models of internationalization have shown limitations in explaining and providing guidance for the success of these types of SMEs in international markets. The vast majority of studies on internationalization were focused on large manufacturing companies (MNCs - Multinational Corporations), as stated by (Andersen and Buvik, 2002). The internationalization of smaller firms and of the service sector, such as of software, also called new technology-based firms (NTBFs) (Bollinger, Hope and Utterback, 1983), has become more focused on research in the past ten years, generally, with results explained from case studies, but with interesting new concepts.

One of these concepts deals with the determinants of internationalization of the "passive" or "active" type, the latter being directly related to innovation and to the qualification of the professionals of the companies. (Roselino, 2006) highlights that in the "active" internationalization, innovation is more concentrated in the host nations, and software products or related services are characterized by high added value, being developed by highly qualified professionals in software engineering. These aspects are of fundamental importance for the "active" internationalization of software companies. (Ronkko, Ojala and Tyrvainen, 2013) say that "Innovation should also be a guideline for internationalization in the software industry". Cases such as Airb$\mathrm{nb}$ and Uber, for example, with value-added technology and services can corroborate such assertions.

In such a scenario, there is a lack of empirical results that allow deepening research on the internationalization of SMEs of innovative or high technology products through the application of quantitative research. This research contributes to the dearth of empirical research on active internationalization in software SMEs context by developing a valid and reliable research scale. The scales were developed in four languages, with reverse translation, and applied in countries whose native languages are English, French, Portuguese or Spanish.

Following the scale development and data collection steps, the managers' perceptions about the internationalization of software SMEs were subject to an exploratory factor analysis (EFA) and confirmatory factor analysis (CFA), enabling the achievement of the final version of the conceptual model (research scale) to assess the internationalization of SMEs. The final research scale is composed by 15 items grouped in 4 dimensions. Reliability and validity measures were also calculated in order to check the adequacy of the proposed model.

The paper starts by reviewing the conceptualization and dimensionality of internationalization of SMEs providing the basis for exploring the content domain of software SMEs. It then explains the methodology followed to collect data through a survey, the scale development, and the analysis procedures to present the psychometric properties of the scale. Concluding remarks highlight theoretical contributions, managerial implications and limitations with avenues for further research also being suggested.

1) Department of Informatics and Statistics (INE), Federal University of Santa Catarina (UFSC), Campus Universitário Trindade, Cx.P. 476, Florianópolis, Brazil

*Corresponding author: M.F.Galimberti@ufsc.br 


\section{Literature review on internationalization of SMEs}

Even though the traditional theories on internationalization of companies do not distinguish small and large companies in the process of expansion into foreign markets, they generally focused on large manufacturing enterprises (Andersen and Buvik, 2002). Nonetheless, within the scope of this paper, it is more appropriate to consider approaches that can be applied to the segment of SMEs, especially software and services. In the beginning, no validated model was found to be applied in quantitative research on the internationalization of SMEs. Thus, this study sought to investigate later internationalization approaches that could better explain the internationalization of software SMEs.

In this context, the proposal of a model based on contemporary approaches to internationalization was found in the work of (Galimberti and Wazlawick, 2015; 2016). This model, presented in Figure 1, was applied in a multiple case study, and seeks to explain the internationalization of the active type, that is, one in which the company that internationalises owns the product and the innovation of the product / service being internationalised. The model is based on the following contemporary approaches: the Innovation-Based Models of internationalization (I-Models) (Bilkey and Tesar, 1977; Cavusgil, 1980; Reid, 1981; Czinkota, 1982); the Networks Model (Johanson and Vahlne, 2003) is an extension to the Uppsala model (Johanson and Vahlne, 1977); the Theory of International Entrepreneurship (Andersson, 2000); and the Born Global approach (Rennie, 1993; Phillips McDougall, Shane and Oviatt, 1994; Madsen and Servais, 1997; Harveston, Kedia and Davis, 2000; Sharma and Blomstermo, 2003; Chetty and Campbell-Hunt, 2004).

From such contemporary approaches, and from interviews with software specialists, the model of Figure 1 was proposed by (Galimberti and Wazlawick, 2016) with four dimensions: innovation, entrepreneurship, relationship network and knowledge about the foreign market. These dimensions were defined with 32 attributes that served as the basis for the scale proposed in section 3 of this paper. For this reason, the concepts related to the attributes present in the model of Figure 1 are synthesized below from the analysis of the original sources adopted by the contemporary approaches mentioned above.

Figure 1: Four dimensions for active internationalization of software SMEs

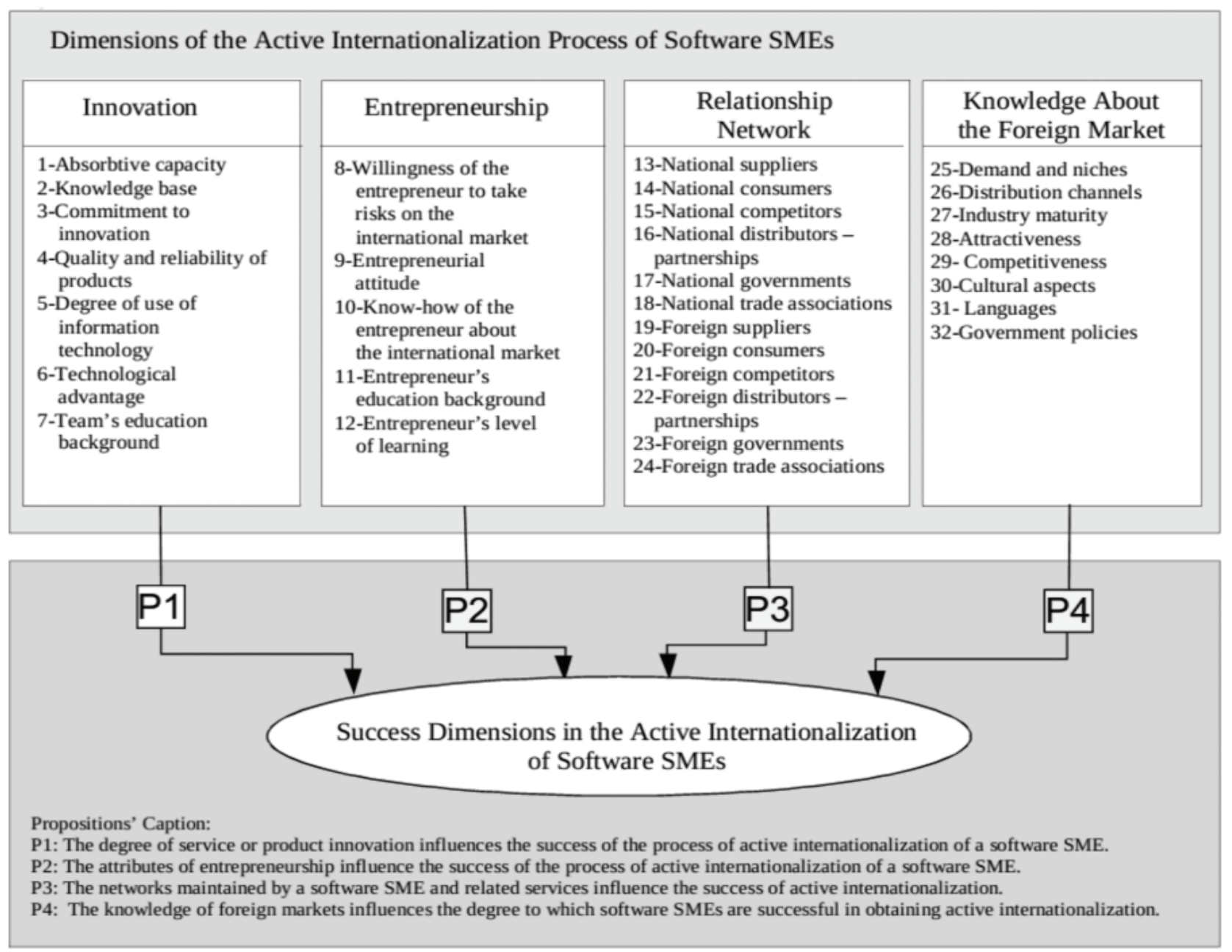

Fonte: (Galimberti and Wazlawick, 2016) 
The first seven attributes of the model try to explain the importance of the Innovation dimension for the internationalization of software SMEs. The first attribute is absorptive capacity (ACAP), which, according to (Zahra and George, 2002; Chetty and Campbell-Hunt, 2004), is a set of four complementary capacities of an organisation, namely acquisition, assimilation, transformation and exploration of knowledge. The second attribute addresses the knowledge base of a company, being the implementation of knowledge assimilation and transformation capacities as determinants for the growth of a company, as discussed in (Jantunen, 2005; Saarenketo et al., 2009). And, although the model is related to absorptive capacity, it treats the first attribute in a disconnected way, as (McDougall, 1989; Rennie, 1993) point out. The following attribute refers to commitment to innovation as the company's effort undertaken in innovative activities, seeking to develop technologically new or improved processes and services or goods, or yet as a strategic decision to internationalise (Galimberti and Wazlawick, 2016). The fourth attribute, which deals with quality and reliability of products, albeit from a Born Global perspective, also refers to the set of attributes of representative qualities of the software engineering subject, which includes reliability (Ghezzi, Jazayeri and Mandrioli, 2003). Attributes five and six are characterized, firstly, by the degree of use of information technology as a means and not as an end to innovation, while the second refers to the technological advantage as an influencer of technological innovation (Galimberti and Wazlawick, 2016). The last attribute of this dimension comes from the proposal of (Roselino, 2006) on active internationalization and tries to explain the importance of the technical team's education background for innovation, being that innovation would be the main characteristic of the company that actively internationalises. (Roselino, 2006) states that "[...] the most complex stages of the process are certainly those that comprehend the software engineering activities, concentrating the most critical phases of production, since the activities of greater technological content would reside in those."

The second dimension brings five attributes related to Entrepreneurship characteristics that might help to explain the success of the internationalization process of software SMEs. Attribute number eight addresses the preferences, motivations and expectations to take risks on the international market (Andersson, 2000). The ninth attribute explicitly refers to the entrepreneurial attitude which would be influenced by the individual characteristics of the entrepreneur (Shane, 1996; Whynes, Ennew and Feighan, 1999), and here it represents not only attitudes, but also experiences, motivations, and behaviours of the decision maker. Attribute number 10 is justified due to the definitions of the authors of the Born Global Perspective that consider the great experience and qualification of the entrepreneur for the international market as determinant for internationalization. The following attribute deals with the entrepreneur's education background for the international market, differing from the know-how of the entrepreneur (previous attribute), but it also relates to the education background in software engineering for designing innovative products, as described above by (Roselino, 2006). The entrepreneur's level of learning characterizes the last attribute of this dimension and has its origin in the three learning categories of (Shiba et al., 1993) and in the
Network Model of (Johanson and Vahlne, 2003), which advocates that the decisions about the process of internationalization are determined directly or indirectly by learning and by the relationships within the local business networks, and expand towards international markets.

The third dimension of research is homonym with the Network model in which (Johanson and Vahlne, 2003) identify the intensity of the company's engagement in relationship networks with suppliers, consumers, competitors, distributors and governments as determinant for internationalization. (Galimberti and Wazlawick, 2016) also added to those the relationship with professional associations, or trade associations, based on observations about the software market and on the suggestion of experts who participated in the case study research. Although such networks were grouped into a single network-related variable within the country of origin of the company, it was broken down into the six attributes from number 13 to 18 of Figure 1. Thus, the research performed could better map the specificities of internationalised companies in relation to network involvement within the country of origin. The same strategy was adopted to define the other six attributes of this dimension of research that deal with relationship networks outside the country of origin, namely the attributes from number 19 to 24. Besides the Network Model, the Innovation-Based Model (Reid, 1981) and the papers on the Born Global Perspective (McDougall, 1989; Rennie, 1993; Sharma and Blomstermo, 2003) also contributed to the structuring of this research dimension.

The fourth, and last dimension, groups five attributes of contemporary literature on internationalization plus the last three that have emerged from direct and indirect observations and suggestions from experts interviewed in the case study research by (Galimberti and Wazlawick, 2016). Attribute number 25 takes into account that knowledge about market niches is considered determinant by (Johanson and Vahlne, 2003) for greater participation in relationship networks, while knowledge about the demand of international markets is relevant for the type of marketing entrepreneur of (Andersson, 2000). The next three attributes are also derived from (Andersson, 2000) when stating that the structure entrepreneur would act in mature industries (attribute 27) and his strategy would be implemented at the corporate level, engaging in the restructuring of industries, motivated by attractiveness (attribute 28) and market competitiveness (attribute 29). As previously mentioned, observations and suggestions have motivated (Galimberti and Wazlawick, 2016) to add to the model attributes that represent cultural aspects, languages and government policies. The first two are justified by recommendations from more than one specialist in the area of software engineering and international software businesses and also because of the importance of the experiences of the born global entrepreneur in other cultures, not to mention the fact that this attribute is also related to specific practices of international markets. As for the last attribute, it would be justified depending very much on the segment in which the software company operates, so they chose to add it to the research model based on the experiences of global software companies. The 32 presented attributes and related concepts constitute the theoretical basis for the construction of the detailed scale of research that follows. 


\section{Research methodology and scale development}

The review of the literature on internationalization focusing on technology SMEs has confirmed the dearth of quantitative studies that would allow a deeper understanding of the subject. Thus, a project was started for the development of research scales and instruments for data collection.
The method used sought to define the criteria for selecting the companies to participate in the data collection, namely those proposed by (Galimberti and Wazlawick, 2016), according to Table 1, adding the criterion that each company must be from a country whose native language is one of the four mentioned, that is English, French, Portuguese or Spanish.

Table 1: Selection criteria of software companies to the research (Galimberti and Wazlawick, 2016)

\begin{tabular}{ll}
\hline Criteria Id & Criteria description \\
\hline C1 & Each company must be characterised as an SME \\
C2 & $\begin{array}{l}\text { Each company must have business results from other countries and must be } \\
\text { sustainable with its activities abroad }\end{array}$ \\
C3 & $\begin{array}{l}\text { Each company must have had international activities for more than } 2 \text { years } \\
\text { C4 }\end{array}$ \\
& $\begin{array}{l}\text { Each company must have a total income compatible with SMEs average } \\
\text { income, regardless the way the company accessed international markets; and } \\
\text { C5 }\end{array}$ \\
& $\begin{array}{l}\text { Each company must have autonomy regarding the high value products or } \\
\text { services it offers }\end{array}$ \\
\hline
\end{tabular}

The next step focused on designing the research scales, followed by validation and adjustments. To validate the instruments at the level of translation and of understanding has been chosen to discuss the data collection instruments by interviewing entrepreneurs of software SMEs. The collection instruments were developed in four languages, namely English, French, Portuguese and Spanish, being initially written in one of the languages and translated to the others afterwards. The translations were done by native speakers of each language. For each language, the translation and back-translation procedure was used to create the other versions of the scale, or cross-national survey instruments, as suggested by (Brislin, 1970). Such procedures were carried out by other people, rather than those who performed the initial translation.

After the instruments were available in the four languages aforementioned, the database was structured from a protocol with the following steps:

- first, countries from the 4 native languages were selected for the first filter, whether they were technologically central or non-central, but which had a recognized and organized software industry, meaning that they had professional associations or associations of software companies that represented it;

- then, there was an effort to identify and analyse information from software associations of such countries as a gateway for the identification of companies of interest;
- $\quad$ in the third stage of the process, companies from the software associations were selected and they were recorded in the database with email addresses and URL;

- the fourth stage proposed that companies would be filtered from the criteria mentioned above so that the data collection itself could be conducted.

Given the size of the data collection, it was estimated that three attempts would be made with the companies. Firstly, emails were sent with instructions for filling the collection instrument. The research tools were developed in GoogleDocs ${ }^{1}$, later being transferred to the LimeSurvey2 tool according to the most appropriate resources for analysis and confirmation of the origin of the data, when allowed by the respondents. A second e-mail contact was conducted in order to highlight the relevance of the research and responsible institution. A third and last attempt was planned to be conducted by telephone, but this was not carried out.

Table 2 presents the complete scale with 34 research items. The 34 items were derived from the 32 attributes of the research model (Galimberti and Wazlawick, 2016), or possibly from concepts that formed such attributes, as discussed in the review section of the literature. Each item was proposed on a 5-point Likert scale where 1 means Completely Disagree and 5 means Completely Agree.

(1) Google Docs ${ }^{\mathrm{Tw}}$ web-based word-processing program

(2) Limesurvey is a free and open source on-line survey application, distributed under the GNU General Public License. (Documentation, 2009). 
Table 2: internationalization of Software Enterprises Scale

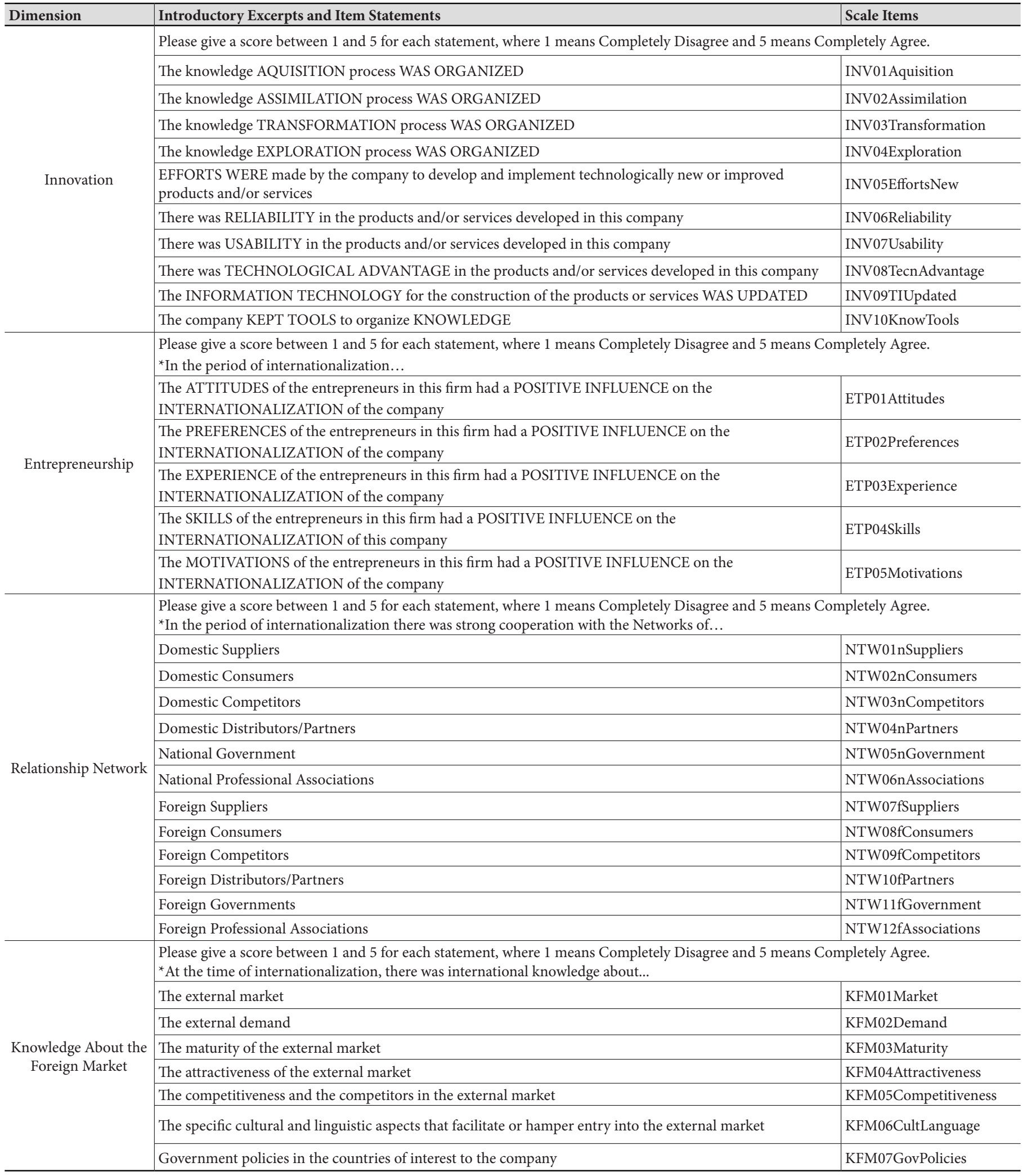


After those steps, and over a year period, 10,059 software SMEs were contacted. For purposes of scale validation, a sample of 103 valid cases was obtained. Although there is a limitation on the size of the sample for the analysis of data results, it is believed to be sufficient for testing the scale itself, as it will be seen in the next section. The next phase is characterized by the activities of greatest interest that are the analysis of data and writing of the results. The strategy of this research encompasses that statistical techniques of multivariate data analysis to be adopted, those that are best suited to the data collected and the purposes of the research have been tested and adopted.

\section{Analysis}

This section presents the results of the exploratory and confirmatory factor analysis conducted to evaluate the quality of the scale proposed in the previous section and to guide adjustments in the model. The section starts by checking the internal consistency of responses obtained during the data collection step and concludes by evaluating the validity of the final conceptual model proposed to evaluate the attributes that contribute to the success in the active internationalization processes of software SMEs.

\subsection{Instrument reliability}

Initially, Cronbach alpha was obtained to assess the internal consistency of the 34 -item scale ( $\alpha=899$ ). Alphas were also computed for every possible version of the scale with a single item removed, the results have shown alpha coefficients ranging from 0.893 to 0.900 . All coefficients were above the minimum acceptable value of 0.70 (Nunnally, 1978). No item produced a substantial increase of the value of alpha when removed, suggesting internal consistency of the scale.

\subsection{Exploratory factor analysis}

The suitability of the dataset for exploratory factor analysis was investigated through the Kaiser-Meyer-Olkin (KMO) measure and the Bartlett's Test of Sphericity, both suggested the data is suitable for factor analysis. The KMO (ranging from 0 to 1 ) achieved a value of 0.771 and thus exceeds the lower threshold required of 0.5 (Kaiser, $1970)$. Bartlett's test $\left(\chi^{2}=2177.4, \mathrm{p}<0.000, \mathrm{df}=56\right)$ provided evidence that the correlation matrix has significant correlations among at least some of the items.

Exploratory factor analysis (EFA) was performed with the sample of 103 respondents, using principal component analysis (PCA) with Promax rotation, which is an oblique rotation appropriate for cases in which the latent variables might be correlated and the goal of the analysis is to identify theoretically meaningful factors (Gorsuch, 1983; Hair, 2010).

The criteria used to indicate the number of factors to retain were the percentage of the variance explained and the Scree plot. Whilst the former criterion suggests a 4 -factor or 5-factor solution, accounting to at least $50 \%-60 \%$ of the variance explained (Hair, 2010), the latter suggests the possibility of 4 (steep downward slopes) or 7 (moderate downward slopes) factor solutions (see Figure 2). We chose the 4 -factor extraction, which accounted for $52.73 \%$ of the total variance. The 4 -factor solution corroborated the initial classification of items in four dimensions proposed by (Galimberti and Wazlawick, 2016).

Figure 2: Eigenvalue plot for the Scree test criterion

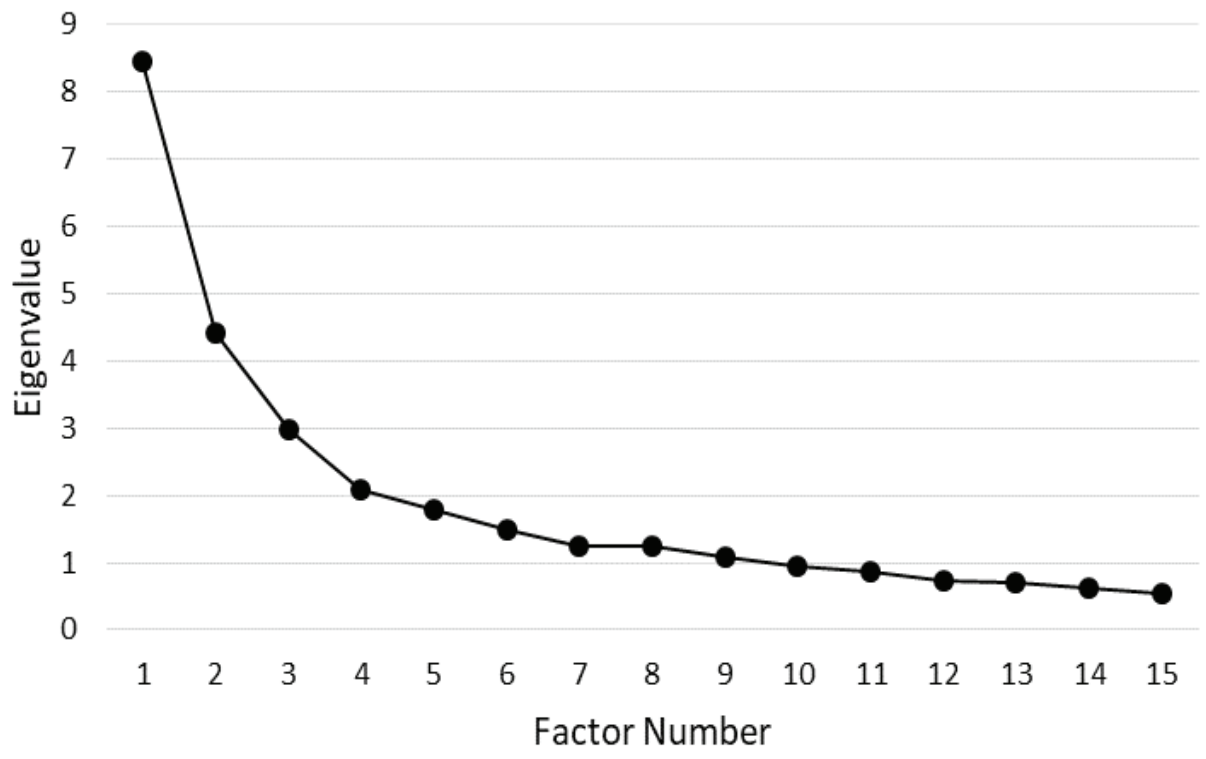

ISSN: 0718-2724. (http://jotmi.org) 
Table 3 presents the factor loadings and the communalities for each item. The loadings higher than 0.50 were highlighted. None of the highlighted items presented cross-loadings, i.e., they are significant to explain a single dimension. Nine of the thirty-four items did not load significantly in any factor. These items seemed to be less important to explain the attributes that contribute to success in the active internationalization processes of software SMEs. As expected, the items that did not load significantly in any factor presented low values of communality, confirming they do not share a significant amount of variance with the remaining items. Therefore, they will not be retained in the analysis. The criteria used to retain the items were defined based on (Hair, 2010) and (Wolfinbarger and Gilly, 2003), indicating that items should load at least 0.50 on one factor and no item should load more than 0.50 on two or more factors.

Table 3: EFA results and cummunalities values

\begin{tabular}{|c|c|c|c|c|c|}
\hline Items & Communalities & Factor 1 & Factor 2 & Factor 3 & Factor 4 \\
\hline INV01Aquisition & .692 & .807 & -.255 & .151 & .144 \\
\hline INV02Assimilation & .724 & .839 & -.155 & .083 & .135 \\
\hline INV04Exploration & .691 & .752 & -.113 & .100 & .256 \\
\hline INV05EffortsNew & .559 & .579 & .362 & -.073 & -.146 \\
\hline INV06Reliability & .423 & .513 & .260 & -.183 & -.140 \\
\hline INV09TIUpdated & .329 & .229 & .498 & .099 & -.203 \\
\hline INV10KnowTools & .441 & .329 & .403 & .145 & .111 \\
\hline ETP01Attitudes & .577 & -.065 & .764 & .016 & .043 \\
\hline ETP02Preferences & .570 & -.130 & .707 & -.038 & .199 \\
\hline ETP03Experience & .578 & -.040 & .610 & .190 & .258 \\
\hline NTW03nCompetitors & .627 & -.089 & -.014 & .833 & -.196 \\
\hline NTW04nPartners & .549 & .233 & -.125 & .697 & -.026 \\
\hline NTW05nGovernment & .523 & -.115 & .006 & .602 & .248 \\
\hline NTW06nAssociations & .548 & -.136 & .040 & .653 & .190 \\
\hline NTW07fSuppliers & .407 & -.116 & .103 & .488 & .260 \\
\hline NTW08fConsumers & .263 & .011 & .236 & .160 & .317 \\
\hline NTW09fCompetitors & .356 & .012 & .066 & .488 & .195 \\
\hline NTW10fPartners & .260 & -.058 & .081 & .190 & .395 \\
\hline NTW11fGovernment & .362 & -.116 & .036 & .414 & .318 \\
\hline NTW12fAssociations & .454 & .003 & -.033 & .362 & .460 \\
\hline KFM01Market & .577 & .089 & .183 & .012 & .652 \\
\hline
\end{tabular}

Factor 1 is composed by items exploring the importance of innovation for the internationalization of software SMEs. Seven items (INV01 to INV07) seemed to be important to explain this dimension, following (Galimberti and Wazlawick, 2016), this dimension was named Innovation. Three items (INV08, INV09 and INV10) also exploring features related to innovation did not load significantly in any dimension.

The second factor shown at Table 3 was named Entrepreneurship. It is composed by five items exploring some characteristics of the entrepreneur that may help explain the success of the process of interna- tionalization of software SMEs. All items in this dimension presented high values of factor loading and, therefore, they revealed to be important to explain this dimension.

Items exploring the company's engagement in relationship networks composed the dimension named Relationship Network. Note that only the items are related to the national network (NTW01 to NTW06) seemed to be relevant to explain this dimension. Items related to relationship networks outside the country of origin (NTW07 to NTW12) did not load significantly in any dimension. 
The last column of Table 3 presents the fourth factor. Seven items seemed to be relevant to explain this dimension. These items explored aspects related to the company's international knowledge about the external market at the time of internationalization. Following (Galimberti and Wazlawick, 2016), it was named Knowledge About the Foreign Market.

Despite the presence of some items with low communalities, we retain them in order to evaluate their performance in the new step of the analysis, the confirmatory factor analysis.

\subsection{Confirmatory factor analysis}

After the EFA and reliability analysis, the reduced version of the instrument containing 25 items was submitted to a confirmatory factor analysis (CFA) to empirically assess the quality of the measurement model and to guide adjustments if necessary.

The CFA model was estimated via the Maximum Likelihood method, using the IBM SPSS Amos software. Tests on construct validity and reliability were also performed.

Following the scale development guidelines, a range of measures were used to assess the model fit, such as Chi-Square statistic, Root Mean Squared Error of Approximation (RMSEA), Standardized Root Mean Square Residual (SRMR), Goodness-of-fit Index (GFI), Adjusted Goodness-of-fit Index (AGFI), Incremental Fit Index (IFI), Normed Fit Index (NFI) and Comparative Fit Index (CFI) (Hair et al., 2006).

The Chi-Square value is a traditional measure for assessing overall model fit, the criterion for acceptance varies among researchers, $\mathrm{Hu}$ and Bentler, 1999) consider a relative Chi-Square $\left(\mathrm{X}^{2} / \mathrm{df}\right)$ value lower than 3 as good. (Ullman and Bentler, 2003) is more rigorous and recommends a value lower than 2. For SRMR and RMSEA measures, values lower than 0.09 and 0.05, respectively, are regarded as good ( $\mathrm{Hu}$ and Bentler, 1999). Concerning GFI and AGFI, thresholds of 0.9 and 0.80 , respectively, are an indication of an acceptable model fit (Byrne and M., 1994; Hu and Bentler, 1999; Hair, 2010). For other fit indices like IFI, NFI and CFI, values of 0.9 or higher represent an acceptable model fit and values of 0.95 or higher are an indication of a good model fit (Byrne and M., 1994; $\mathrm{Hu}$ and Bentler, 1999).

For the initial model composed by 25 items, fit measures indicated an unsatisfactory fit between the measurement model and the data. Thus, an iterative elimination process was carried out. Items were deleted one by one and the fit measures were recalculated based on the low loadings presented by some items, the standardized residuals, and the modification indices. As a result, a total of 10 items were deleted. Figure 3 presents the final path diagram of the estimated model.
Figure 3: Path diagram of the final estimated model.

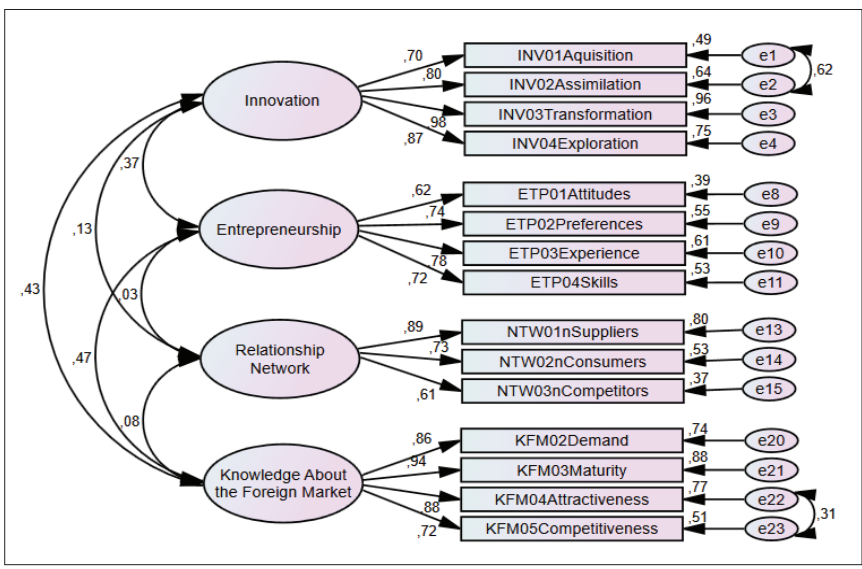

After the removal of 10 items, the measurement model demonstrated satisfactory levels of fit. Table 4 shows the values of the fit measures calculated for the final model presented in Figure 3.

Table 4: Fit indices for the final estimated model

\begin{tabular}{c|c|c|c|c|c|c|c|c|c}
\hline$\chi_{2}$ & df & $\chi^{2} / \mathrm{df}$ & RMSEA & SRMR & GFI & AGFI & IFI & NFI & CFI \\
\hline 106.29 & 82 & 1.30 & 0.05 & 0.06 & 0.89 & 0.84 & 0.97 & 0.90 & 0.97 \\
\hline
\end{tabular}

\subsection{Construct validity}

Finally, the correlations between the constructs, the Average Variance Extracted (AVE), and the Composite reliability (CR) were calculated in order to assess the construct validity of the proposed model. Evidence of construct validity indicates that items measures obtained from the sample represent the real measures that exist in the population (Hair, 2010). The reliability and validity measures were calculated and assessed following the formulas and recommendations presented in (Fornell and Larcker, 1981) and (Hair, 2010).

The correlation coefficients between the constructs of the proposed model were all lower than 0.8 (they range from 0.03 to 0.47 ), satisfying the (Bagozzi, R. P., \& Yi, 1988) recommendation. The AVE measures for all factors seemed to be greater than the threshold of 0.5 (Innovation: 0.71; Entrepreneurship: 0.52; Relationship Network: 0.57; Knowledge About the Foreign Market: 0.72). In addition, the AVE estimates for each two factors were always greater than the square of the correlation between the two factors, as recommended by (Fornell and Larcker, 1981).

The model presented CRs above the minimum of 0.7 for all dimensions, suggesting the internal consistency of each dimension (Innovation: 0.91; Entrepreneurship: 0.81; Relationship Network: 0.79; Knowledge About the Foreign Market: 0.72). These results, combined with the standardized CFA loadings of the items on their dimensions, support the convergent validity of the scale. As shown at Table 5, all standardized loadings are above the acceptable threshold of 0.5 and almost all of them are above the ideal threshold of 0.7 . 
Table 5: CFA results and validity measures

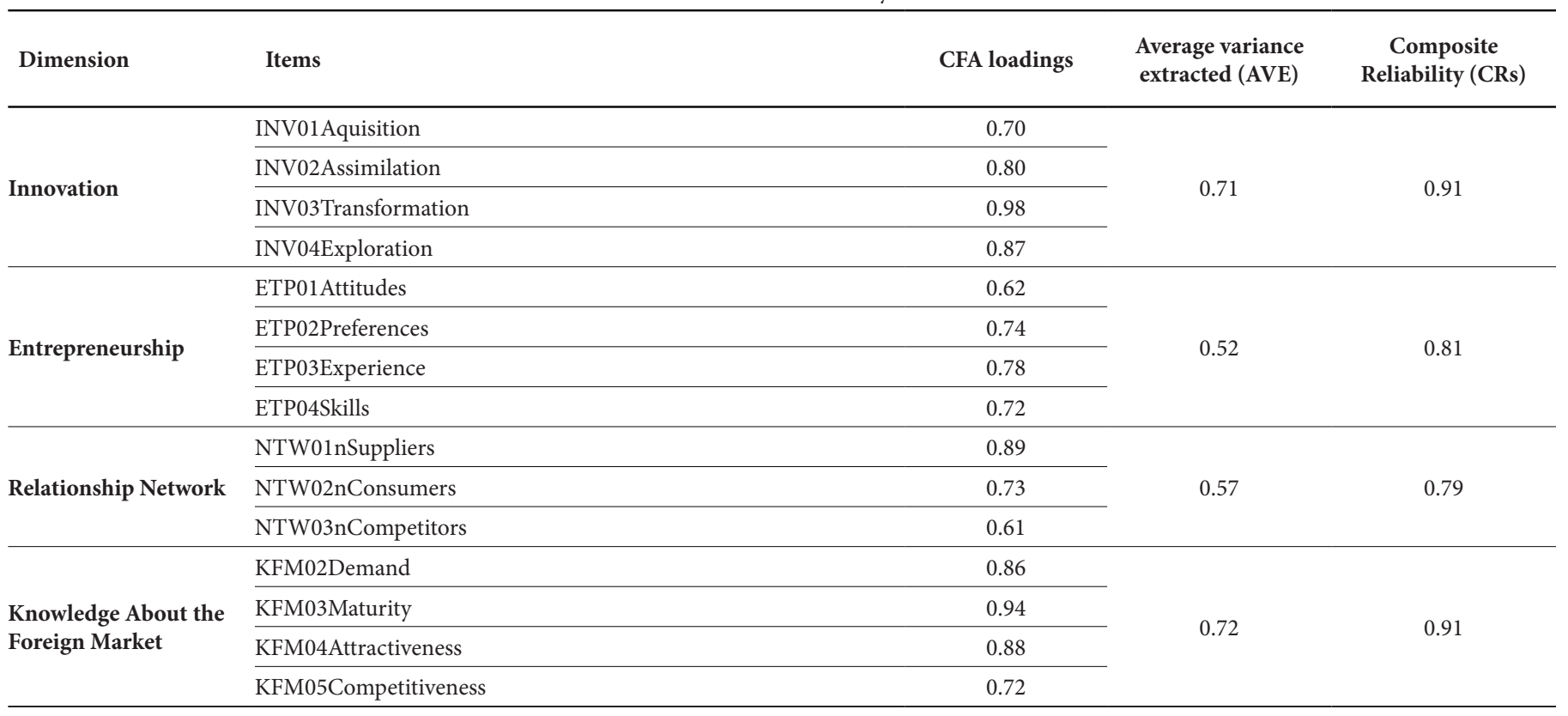

The validity measures calculated are within the acceptable levels, supporting the validity of the construct. Therefore, the 15 items shown at Table 5 compose the final version of the research scale. These items proved to be important to explain the success in the active internationalization processes of software SME.

\section{Discussion and conclusions}

The factor analysis, first applied in an exploratory perspective, revealed four meaningful factors to explain the success of software SMEs in active internationalization processes. The first factor aggregated items related to Innovation; the second factor, items related to Entrepreneurship; the third factor, items related to Relationship Network; and, the fourth factor aggregated items related to Knowledge About the Foreign Market. The classification of the items in four factors corroborated the four-dimension research model proposed by (Galimberti and Wazlawick, 2016).

The four-factor solution identified 25 of 34 items as the most representative to explain the success in active internationalization processes. These results obtained in the exploratory analysis were subject to a confirmatory factor analysis in order to assess the quality of the measurement model obtained. In this step, following the scale development guidelines, 10 items were deleted in order to achieve a reliable and valid measurement scale. The final version of the research scale, composed by 15 items grouped in 4 dimensions, represent a tested and validated measurement model to explain the success of software SMEs in active internationalization processes, and, therefore, can be used in future surveys.

It can be noticed that the analysis performed suggests that the research scale maintains, in the innovation and entrepreneurship factors, almost all attributes of the research model that it is based on.
On the other hand, the network factor is presented from only 3 attributes, out of a total of 12 , with only aspects of national networks being maintained in the research scale. As well as international networks, the attributes of the dimension that deals with knowledge about the international market that had greater relevance refer to knowledge about demand, maturity, attractiveness and competitiveness of the market that seeks to internationalise, out of a total of 8 attributes. It is believed that these particularities observed in the scale tested can characterise important contributions to theories related to the internationalization of SMEs.

In managerial terms, it is believed that the article has much to contribute to the segment of software SMEs. Although this segment stands out with new business models and with technological advances, researches that explain the internationalization of software SMEs are scarce or inadequate.

The size of the sample can be characterised as a limitation of the present article. However, it should be considered that this limitation is not relevant at this moment of the research, because the data were analysed solely with the intention of validating the research scale itself through a confirmatory factorial analysis, which was satisfactory.

validated scale presented in this article opens up many possibilities for future research. The main ones may be the application in surveys that seek to better explain the behaviour of small and medium-sized software companies in international markets with larger samples. Finally, it is envisaged that such research scales may be adapted to companies in other sectors, or yet that they may serve to surveys that deal separately with the attributes of the dimensions of innovation, entrepreneurship, networks, and knowledge about foreign markets. 


\section{Acknowledgments}

This paper partly sponsored by UFSC - Universidade Federal de Santa Catarina and FAPERGS - Fundação de Amparo à Pesquisa do Estado do Rio Grande do Sul (FAPERGS). The final revision of the English version was done by Letícia Lanius.

\section{References}

Andersen, O. and Buvik, A. (2002) 'Firms' internationalization and alternative approaches to the international customer/market selection', International Business Review, 11(3), pp. 347-363. http://dx.doi. org/10.1016/S0969-5931(01)00064-6.

Andersson, S. (2000) 'The internationalization of the firm from an entrepreneurial perspective', International Studies of Management and Organization, pp. 63-92. Available at: http://www.scopus.com/ inward/record.url?eid=2-s2.0-0012814740\&partnerID=tZOtx3y1.

Bagozzi, R. P., \& Yi, Y. (1988) 'On the evaluation of structural equation models', Journal of the Academy of Marketing Science. http:// dx.doi.org/10.1177/009207038801600107.

Bilkey, J. and Tesar, G. (1977) 'The export behavior of smaller Wisconsin manufacturing firms', Journal of International Business Studies1, 9(1), pp. 93-98.

Bollinger, L., Hope, K. and Utterback, J. M. (1983) 'A review of literature and hypotheses on new technology-based firms', 12(1), pp. 1-14. http://dx.doi.org/10.1016/0048-7333(83)90023-9.

Brislin, R. W. (1970) 'Back-Translation for Cross-Cultural Research', Journal of Cross-Cultural Psychology, 1(3), pp. 185-216. http://dx.doi. org/10.1177/135910457000100301.

Byrne, B. M. and M., B. (1994) Structural equation modeling with EQS and EQS/Windows : basic concepts, applications, and programming. Sage Publications. Available at: https://dl.acm.org/citation. cfm?id=528620 (Accessed: 29 September 2017).

Cavusgil, S. (1980) 'On the Internationalization Process of Firms', European Research, 8, pp. 273-281.

Chetty, S. and Campbell-Hunt, C. (2004) 'A Strategic Approach to Internationalization: A Traditional Versus a "Born-Global" Approach', Journal of International Marketing, 12(1), pp. 57-81. Available at: http://www.scopus.com/inward/record.url?eid=2-s2.01642387422\&partnerID=tZOtx3y1.

Czinkota, M. (1982) 'Export development strategies: US promotion policy'. Available at: https://scholar.google.com/scholar? cluster $=737$ 3618366045398112\&hl=en\&oi=scholarr\#0 (Accessed: 9 April 2015).

Fornell, C. and Larcker, D. F. (1981) 'Evaluating Structural Equation Models with Unobservable Variables and Measurement Error Evaluating Structural Equation Models with', Source Journal of Marketing Research Journal of Marketing Research This. http://dx.doi. org/10.2307/3151312.
Galimberti, M. F. and Wazlawick, R. S. (2016) 'Success factors for active internationalization of small and medium-sized software enterprises: case analyses from France and Brazil', International Journal of Management and Enterprise Development, 15(4), p. 259. http://dx.doi. org/10.1504/IJMED.2016.079850.

Galimberti, M.F. and Wazlawick, R.S. (2015) 'Active internationalisation of small and medium-sized software enterprises: cases of French software companies', Journal of Technology Management \& Innovation, Vol. 10, No. 4, p.99-108. http://dx.doi.org/10.4067/S071827242015000400011

Ghezzi, C., Jazayeri, M. and Mandrioli, D. (2003) Fundamentals of software engineering. Prentice Hall.

Gorsuch, R. L. (1983) Factor analysis (2nd ed.). Hillsdale, NJ: Lawrence Erlbaum Associates.

Hair, J. F. (2010) Multivariate data analysis. Prentice Hall.

Harveston, P. D., Kedia, B. L. and Davis, P. S. (2000) 'Internationalization of Born Global and Gradual Globalizing Firms: The Impact of the Manager', Advances in Competitiveness Research. American Society for Competitiveness, 8(1), p. 92.

Hu, L. and Bentler, P. M. (1999) 'Cutoff criteria for fit indexes in covariance structure analysis: Conventional criteria versus new alternatives', Structural Equation Modeling: A Multidisciplinary Journal. http://dx.doi.org/10.1080/10705519909540118.

Jantunen, A. (2005) 'Knowledge-processing capabilities and innovative performance: an empirical study', European Journal of Innovation Management. Emerald Group Publishing Limited, 8(3), pp. 336-349. http://dx.doi.org/10.1108/14601060510610199.

Johanson, J. and Vahlne, J. (1977) 'The internationalization process of the firm: a model of knowledge and increasing foreign market commitments', Journal of International Business Studies, 8(1), pp. 23-32. https://doi.org/10.1057/palgrave.jibs.8490676

Johanson, J. and Vahlne, J.-E. (2003) 'Business Relationship Learning and Commitment in the Internationalization Process', Journal of International Entrepreneurship. Kluwer Academic Publishers, 1(1), pp. 83-101. http://dx.doi.org/10.1023/A:1023219207042.

Kaiser, H. F. (1970) 'A second generation little jiffy', Psychometrika. Springer-Verlag, 35(4), pp. 401-415. http://dx.doi.org/10.1007/ BF02291817.

Madsen, T. K. and Servais, P. (1997) 'The internationalization of Born Globals: An evolutionary process?', International Business Review, 6(6), pp. 561-583. http://dx.doi.org/10.1016/S0969-5931(97)00032-2.

McDougall, P. P. (1989) 'International versus domestic entrepreneurship: New venture strategic behavior and industry structure', Journal of Business Venturing, 4(6), pp. 387-400. http://dx.doi. org/10.1016/0883-9026(89)90009-8. 
Nunnally, J. C. (1978) Psychometric theory. McGraw-Hill. Available at: https://books.google.com.br/books/about/Psychometric_theory. html?id=WE59AAAAMAAJ\&redir_esc=y (Accessed: 29 April 2018).

Phillips McDougall, P., Shane, S. and Oviatt, B. M. (1994) 'Explaining the formation of international new ventures: The limits of theories from international business research', Journal of Business Venturing, 9(6), pp. 469-487. http://dx.doi.org/10.1016/0883-9026(94)90017-5.

Reid, S. D. (1981) 'The Decision-Maker and Export Entry and Expansion', Journal of International Business Studies. Nature Publishing Group, 12(2), pp. 101-112. http://dx.doi.org/10.1057/palgrave. jibs.8490581.

Rennie, M. W. (1993) 'Born Global', The McKinsey Quarterly. McKinsey \& Company, Inc., (4), p. 45. Available at: https://www.questia.com/ library/journal/1G1-15424561/born-global (Accessed: 9 April 2015).

Ronkko, M., Ojala, A. and Tyrvainen, P. (2013) 'Innovation as a driver of internationalization in the software industry', in 2013 International Conference on Research and Innovation in Information Systems (ICRIIS). IEEE, pp. 49-54. http://dx.doi.org/10.1109/ ICRIIS.2013.6716684.

Roselino, J. E. (2006) A Indústria de Software: o 'modelo brasileiro' em perspectiva comparada. Universidade Estadual de Campinas.

Saarenketo, S. et al. (2009) 'A knowledge-based view of growth in new ventures', European Business Review. Emerald Group Publishing Limited, 21(6), pp. 531-546. http://dx.doi. org/10.1108/09555340910998823.
Shane, S. (1996) 'Explaining Variation in Rates of Entrepreneurship in the United States: 1899-1988', Journal of Management. Sage PublicationsSage CA: Thousand Oaks, CA, 22(5), pp. 747-781. http:// dx.doi.org/10.1177/014920639602200504.

Sharma, D. D. and Blomstermo, A. (2003) 'The internationalization process of Born Globals: a network view', International Business Review, 12(6), pp. 739-753. http://dx.doi.org/10.1016/j.ibusrev.2003.05.002.

Shiba, S. et al. (1993) A new American TQM : four practical revolutions in management. Productivity Press.

Ullman, J. B. and Bentler, P. M. (2003) 'Structural Equation Modeling', in Handbook of Psychology. Hoboken, NJ, USA: John Wiley \& Sons, Inc. http://dx.doi.org/10.1002/0471264385.wei0224.

Whynes, D. K., Ennew, C. T. and Feighan, T. (1999) 'Entrepreneurial attitudes of primary health care physicians in the United Kingdom', Journal of Economic Behavior \& Organization, 38(3), pp. 331-347. http://dx.doi.org/10.1016/S0167-2681(99)00013-X.

Wolfinbarger, M. and Gilly, M. C. (2003) 'eTailQ: Dimensionalizing, measuring and predicting etail quality', Journal of Retailing. JAI, 79(3), pp. 183-198. http://dx.doi.org/10.1016/S0022-4359(03)00034-4.

Zahra, S. A. and George, G. (2002) 'Absorptive Capacity: A Review, Reconceptualization, and Extension', The Academy of Management Review. Academy of Management, 27(2), p. 185. http://dx.doi. org/10.2307/4134351. 